\title{
A Study on the Construction of City-Gas Smart Disaster Prevention System Based on GIS
}

\author{
Park Jong Tak ${ }^{\mathrm{i}}$ and Kim Chang Soo $^{2 *}$ \\ ${ }^{1}$ Graduate School of MOT, Pukyong National University, Pusan 48513, S. Korea \\ ${ }^{2}$ Dept of IT convergence and Application Engineering, Pukyong National \\ University, Pusan 48513, S. Korea \\ Ijtpark@sk.com, ${ }^{2}$ cskim@pknu.ac.kr
}

\begin{abstract}
With the rapid development of industrial and urban, the issue related with optimization and systematic operation of city-gas safety management system together with the safety consciousness and its associated social responsibility has been raised a lot recently. The buried city-gas pipeline network in densely populated areas poses serious potential hazards of gas leak, dispersion, explosion and fire from internal and external variables on the pipeline itself. This paper takes a look at the various types of accidents from the buried city-gas pipeline network by utilizing big data. It also looks at how global top level gas distributors tackle this issue with its own policy, product standard and regulatory reform. Ultimately in order to protect their property damage and casualties from the citygas accidents, this paper suggests the construction of the GIS-based Smart Disaster Prevention System (SDPS) which analyzes and assesses the influence range of an accident with Risk Assessment Information System (RAIS) and Pipeline Leak and Explosion Detection System(PL\&EDS). In addition, I would also like to suggest the efficient operation environment for the SDPS to minimize gas-related accidents which are upward trends with the increase of gas consumption [1-2].
\end{abstract}

Keywords: SDPS (smart disaster prevention system), PL\&EDS (pipeline leak and explosion detection system), EMS (emergency management system)

\section{Introduction}

City gas, which has a wide spectrum of usage for residential, commercial and industrial, is urban infrastructure which provides clean, convenient and safe energy for people's everyday life. But due to lack of infrastructure, technology, and related policy coupled with poor management practice, the disaster prevention system which detect gas leak and explosion may not work properly when there is an accident in densely populated areas. In order to tackle the issue mentioned above, the mutual friendly relations among government, private enterprises and citizens are required. In other words, the government should strictly perform the checkup and inspection followed by enforcements of policy, the private enterprises should establish safety management system that runs flawlessly and citizens should enhance the safety consciousness for city-gas. In conclusion, now is the time needed to construct smart disaster prevention system by GIS-based city-gas leak and explosion real-time monitoring for responding effectively to ensure the safety of citizens and the safety environment, and being able to protect the lives and property of the people from the city-gas accidents [2-3]. 


\section{Related Research and Technology Trends}

\subsection{Gas Accidents Status and Damage Analysis}

The full gas accidents and the city-gas accidents (an average of 20\%) for the past 5 years have shown a tendency to decline gradually. The casualties caused by the city-gas accidents are significantly reduced as 1.4 people on average per city-gas accident, the city-gas accidents caused by third party construction showed 3.6 accidents an average per year, and the city-gas accidents caused by gas leak, explosion and fire occupy most of the city-gas accidents as $77.8 \%$ of full gas accidents. Table 1 presents the full gas accident facts together with the city-gas accidents status and damage analysis including types of accidents and its collateral damage for the past 5 years [4].

Table 1. The Full Gas Accident Facts

\begin{tabular}{|c|c|c|c|c|c|c|c|c|c|c|}
\hline & & 2011 & & 2012 & & 2013 & & 2014 & & 2015 \\
\hline classification & & $\begin{array}{c}\text { rate of } \\
\text { change } \\
(\%)\end{array}$ & & $\begin{array}{c}\text { rate of } \\
\text { change } \\
(\%)\end{array}$ & & $\begin{array}{c}\text { rate of } \\
\text { change } \\
(\%)\end{array}$ & & $\begin{array}{c}\text { rate of } \\
\text { change } \\
(\%)\end{array}$ & & $\begin{array}{c}\text { rate of } \\
\text { change } \\
(\%)\end{array}$ \\
\hline full gas accidents & 126 & - & 125 & - & 121 & - & 120 & - & 118 & - \\
\hline city-gas accidents & 25 & 19.8 & 31 & 24.8 & 20 & 16.5 & 28 & 23.3 & 19 & 16.1 \\
\hline $\begin{array}{l}\begin{array}{l}\text { human } \\
\text { damage } \\
\text { (people) }\end{array} \\
\end{array}$ & 59 & - & 49 & - & 32 & - & 23 & - & 14 & - \\
\hline $\begin{array}{l}\text { third party } \\
\text { construction }\end{array}$ & 3 & 2.4 & 3 & 2.4 & 2 & 1.7 & 6 & 5.0 & 4 & 3.4 \\
\hline $\begin{array}{c}\text { gas leak/ } \\
\text { explosion/fire } \\
\text { (accidents) }\end{array}$ & 94 & 74.6 & 99 & 79.2 & 107 & 88.4 & 100 & 83.4 & 85 & 63.2 \\
\hline
\end{tabular}

\subsection{City-gas Leak \& Explosion Real-time Monitoring}

There are a lot of methods to detect the gas leak and explosion from city-gas underground pipeline such as the optical sensor (OS), acoustic emission (AE) and ultrasonic technology. More papers are currently underway using the methods mentioned above both abroad and here at home [5-6].

\subsubsection{Optical Sensor}

There are a lot of systems developed and applied to the study that introduces the concept of FENCELINE monitoring considering the surrounding environment and the isolation of hazardous chemicals in developing a system to detect city-gas leak and explosions by the United States, France, Sweden, etc.. And these ways analyze the concentration of hazardous chemicals at the contact long distance by introducing absorption spectroscopy to use a wide range of light sources with ultraviolet ray, visible 
ray, infrared radiation, etc. On the other hand, the safety related technologies due to high interest in safety on the domestic level are developed and introduced, but it is being carried out with fragments, and it is somewhat lacking of industrial know-how compared to developed countries in terms of the core technologies of remote monitoring [5].

\subsubsection{Acoustic Emission}

A lot of studies on the application of AE technology in developed countries, including the United States, Japan, Europe, etc.. have been in progress in the industrial workplace, such as the pipeline, pressure vessel and nuclear power plants. In addition, many studies are under the commercialization steps, but on the domestic side, a small number of $\mathrm{AE}$ systems have been applied to introduce from advanced countries in some workplace, it is somewhat lacking of the industrial field application due to the complexity and high price of the system considering the characteristics of the facility. Because most of the facility design, production and application are dependent on foreign technology, the domestic research and development is urgently needed, in addition to the development of new technologies associated with the AE technology will be promoted in the future.

\subsubsection{Ultrasonic Technology}

In the past 20 years, the ultrasonic gas leak detection has become established as a leading method for plugging the gaps in gas detection system effectiveness and latest advancement in ultrasonic sensing technology. The ultrasonic gas leak detection technology has several advantages over other technologies including detection before hazardous concentrations occur, weather, wind direction and noise insensitivity, detection not requiring immersion in vapor cloud, and a wider coverage radius up to 40 meters. Despite the detection technique's advantages, the acoustic sensing technology faces several limitations including; restriction to pressurized systems, distinction on what is leaking such as air, nitrogen, methane, etc. and time delay adjustments to address pressure release conditions.

\subsection{Assessment and Analysis of Accident Influence Range}

The assessment of the influence range by accidents is done by the following order. The risk factors assessment, the leak analysis, the influence range prediction and assessment by the diffusion, fire, and explosion model, the analysis of the influence range assessment results. The Assessment should include both the basic data such as amount of leak, leak duration, and weather condition and the advanced data such as over pressure, radiation heat, and gas density in order to effectively predict the influence range [7-9].

\subsubsection{Risk Factors Assessment}

This is a step to assess the quantitative or qualitative risk about the risk that exists of the facilities or processes. There are a lot of ways to assess the riskiness. For example, check list method, HAZOP (hazard and operability) and preliminary hazard analysis.

\subsubsection{Leak Analysis}

This is a step to analyze how to leak the hazardous chemicals at the related facilities or process after risk assessment. The leak analysis is calculated by the hazardous chemicals volume, temperature, density, time, leak status (gas, steam, liquid, mixture), etc. The emitted to check the potential leak sources from the pipeline damage, flange leak, safety valve operation, operator mistake, etc. The steam of leak hazardous chemicals is generally divided into the instant emission and the continuous emission by leak time, and the light gas and the weight gas by the density. The leak volume shall be calculated by applying 
the hydrodynamics about steam or gas phase, liquid phase and 2-phase status according to some case the leak in a pipeline and the leak in a facility.

\subsubsection{Prediction and Assessment of the Influence Range}

Predict the explosion influence range, the fire according to the overpressure, the radiation heat using fire model or explosion model if the leak hazardous chemicals are the flammable gases and liquids. There are 3 models of the influence range assessment. For instance, diffusion model (Gaussian plume model: leak of toxic substances), fire model (API Jet fire model: leak off flammable gases and liquids) and explosion model (TNO multi-energy model: leak of flammable gases and liquids).

\subsubsection{Analysis of the Influence Range Assessment Results}

Provide the prediction model used by influence range prediction results. The name of a software also provides together if you've used the commercial software. Shall include the following data which is able to predict the basic data of prediction model using influence range calculation, the leak volume, the leak time, weather condition, etc. and the influence range caused by the postulated accident, the overpressure according to the distance, radiation heat, concentration of toxic substance, etc.. in the data of influence range prediction results, such as wind direction and speed, atmospheric stability, temperature and humidity, leak substance name, volume and rate, end point (end effect point), and influence range prediction results. In addition, it shall also include the following data in the data of influence range prediction results. For example, the diffusion (the concentration according to the distance), pool fire (the distance according to the diameter of liquid level, radiation), jet fire (the distance according to the length of flame, radiation), explosion of boiling liquid, fire ball (the distance according to fireball diameter, height and duration, radiation), vapor cloud explosion (VCE, the overpressure according to the distance), etc. [7].

\section{Construction Model and Methods of SDPS}

This paper describes the construction direction of the smart disaster prevention system (SDPS). This system is a next-generation intelligent safety management system that can provide the quick response capability and needful information in real-time about any types of disasters and accidents, and the ways that could be linked to enable visual management by providing real-time information to $\mathrm{CEO}$, manager and operator.

\subsection{SDPS Whole Schematic Diagram Based on GIS}

Figure 1 presents the whole schematic diagram of the SDPS based on GIS that utilizes all the data mentioned above via central monitoring \& control room, and also describes the construction model and methods of the progress of SDPS that has a lot of attention and developments, and also necessary to minimize city-gas related accidents and disasters [10-12]. 


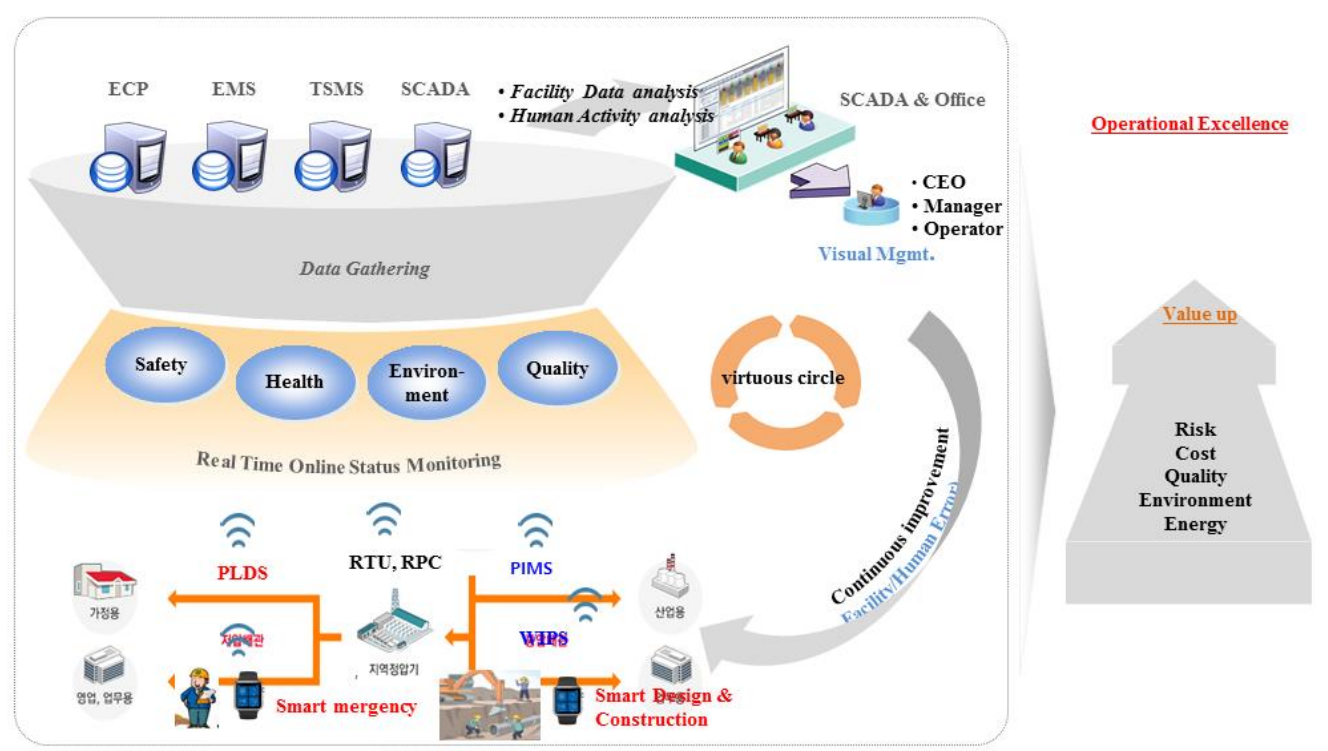

Figure 1. SDPS Whole Schematic Diagram

\subsubsection{Engineering Construction Procurement (ECP)}

ECP is an overall activity that is performed to design, construction and procurement services for city-gas facility, breakdown of cost estimation, construction management, ebidding service, procurement management, partners management, etc..

\subsubsection{Emergence Management System (EMS)}

EMS could be linked to enable visual management by providing real-time information, the blocking valve number and location, the city-gas interrupt customer number and location, etc. to patroller, manager and operator in order to minimize the damage from accidents in the event of an emergency.

\subsubsection{Web Total Safety Management System (TSMS)}

TSMS performs a comprehensive safety management function to sophisticated simulation for complex network system of city-gas supply pipeline, supply availability and pipeline route analysis, pipeline network analysis, supplier and user facility management, facility statistics analysis, emergency response system operation, customer information management, potential customer management, etc.

\subsubsection{Supervisory Control and Data Acquisition (SCADA)}

SCADA should perform the data collection and analysis role in order to prevent the recurrence of accidents and to do well in a rapid emergency response in the event of an emergency through the real-time monitoring of city-gas' main facilities and third party construction by maintaining an emergency situation work system 24 hours a day, abnormal operation situation monitoring of governor, working pressure, operation condition, etc. 


\subsection{Raw Data Acquisition and Application}

Figure 2 shows the raw data acquisition and application flow diagram of the pipeline leak and explosion detection system (PL\&EDS) which is able to detect and transmit an emergency situation from the city-gas leak and explosion initial point by many kinds of sensors. The role of application data system sends the raw data and the city-gas operation $\&$ maintenance data collected and analyzed in real-time from the PL\&EDS to the SDPS $[5-6,12]$.

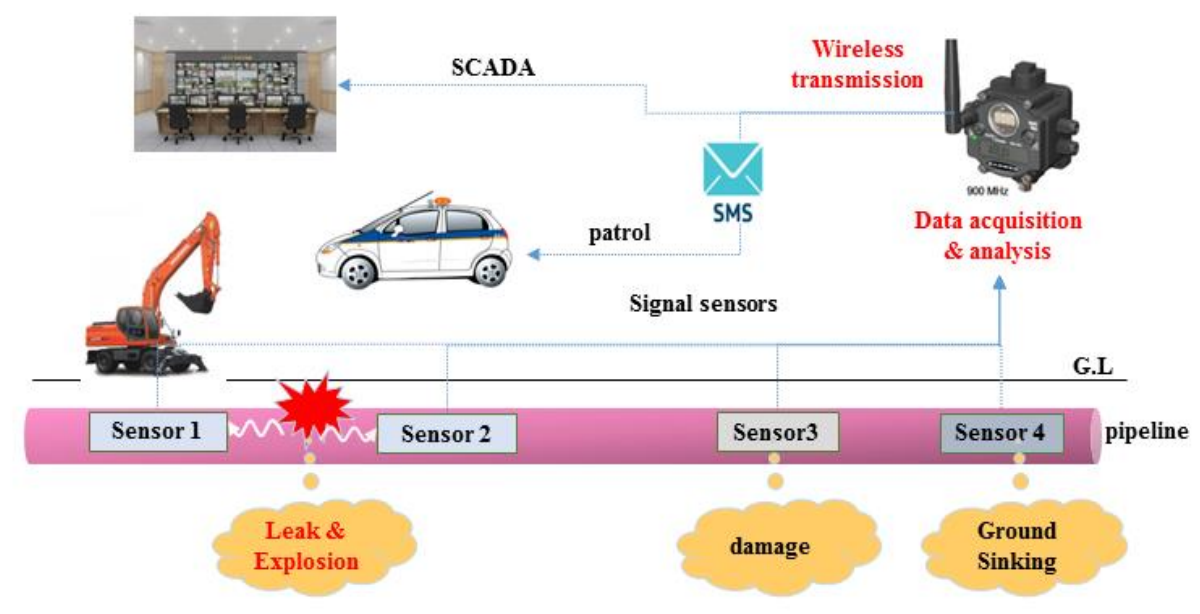

Figure 2. Raw Data Acquisition and Application Flow Diagram

\subsection{Assessment and Analysis of City-gas Disaster Status}

Figure 3 presents the city-gas disaster assessment and analysis drawings which is able to assess and analysis the city-gas disaster status using the integrated DB established by mutual interface, GIS, PL\&EDS, supervisory control and data acquisition system (SCADA), etc.

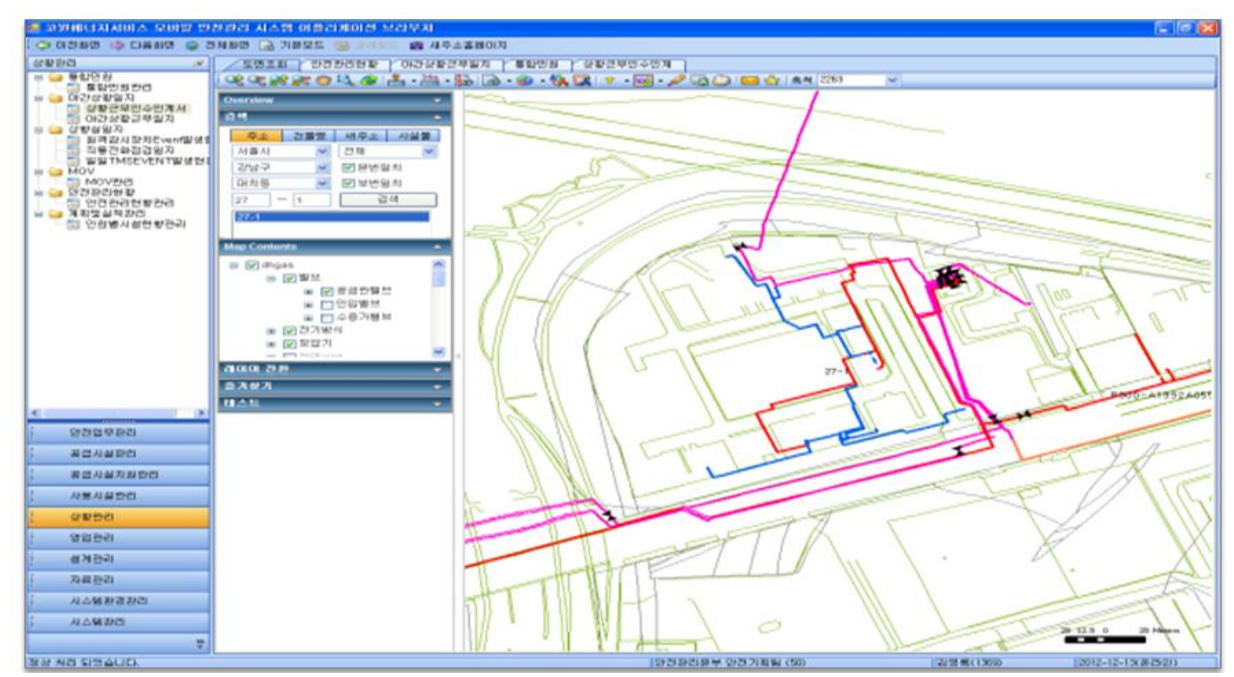

Figure 3. Disaster Status Assessment and Analysis Drawing 


\subsubsection{Pipeline Map (PM)}

PM is a program to diagnose the life of the pipeline and to set up the maintenance standards through the direct, indirect pre and post assessment based on the pipeline maintenance history, inspection history, gas leak test and thickness measurement results, etc.

\subsubsection{Pipeline Network Analysis}

The deviation of measured pressures in pipeline networks from normal or reference pressures is useful information for judging the operation of the pipeline networks. A costeffective monitoring of pipeline networks including a leak detection capability can be realized when transient pressure variation is accurately predicted using measured conditions at supply- and demand-sides of the networks. And it can detect the city-gas pressure and flow rate forecast within pipeline based on the gas usage, supply capacity decision of the pipeline, optimum design of pipeline, customer's gas consumption calculation of users based on the ERP, etc.

\subsubsection{Stress Analysis}

This service is a program that prevents in advance the city-gas facilities damage by analyzing a variety of stress affecting the pipeline, governor and valve due to ground sinking. It also predicts the city-gas' life, according to the increase in the number of use in years for supply facility, buried pipeline, governors, valves, etc. It also judges the criteria for continued use and its availability, which have been insufficient for the operation of an effective safety management system, determination of optimal interval of replacement, inspection checking criteria, etc. The anticipative accident prevention through a systematic stress analysis of the facility, assurance of the pipeline integrity and technology development activities for systematic operation and maintenance work in the field is progressing rapidly.

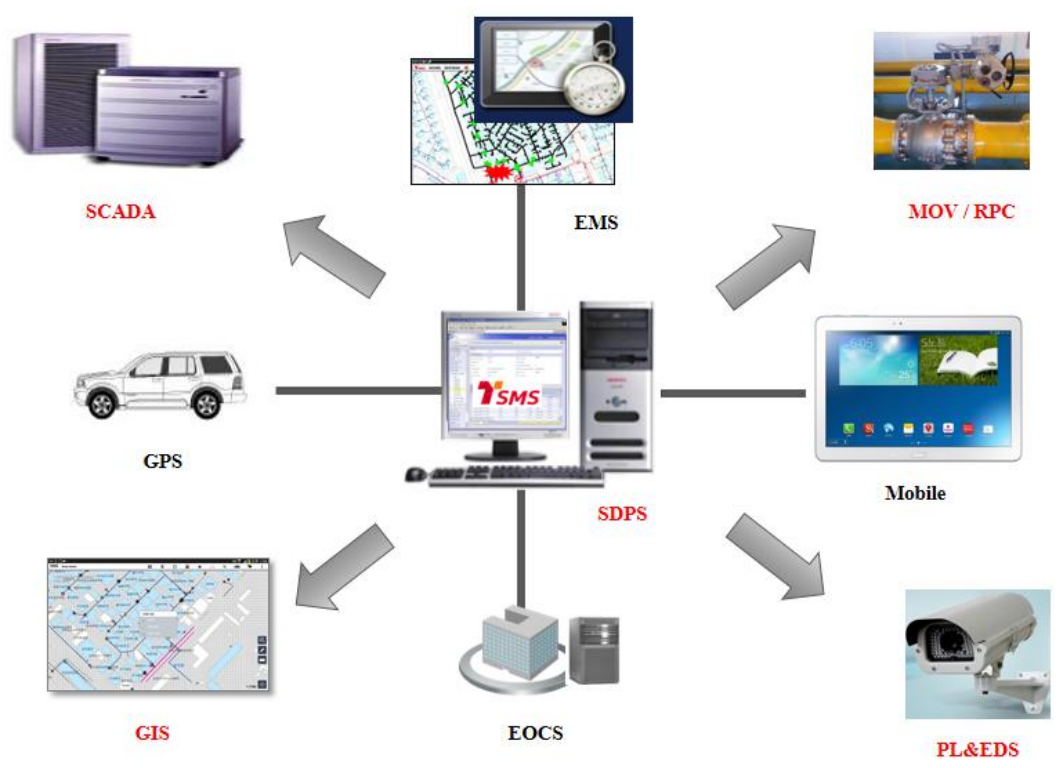

Figure 4. SDPS Application System Schematics Diagram 


\subsection{Application of the Assessment Results}

Figure 4 shows the schematic diagram of the SDPS application system which operates the emergency management system, motor operated valve (MOV), SCADA, e-GIS, mobile field support system, and risk management system which utilizes applied information from PL\&EDS using many kinds of sensors at the underground pipeline and gas related facilities with communication module [10].

\subsubsection{Excavation One Call System (EOCS)}

The system utilizes the phone and internet to transfer information about digging underground and buried gas pipelines, although currently written forms are used in accordance with the city-gas business law. After one year, we evaluated the business model by surveying the excavators and the operators of the gas companies.

\subsubsection{Global Positioning System (GPS)}

GPS is a global navigation satellite system that can support the scene of accident quickly by grasping the position of the patrol car near the accident area as real-time through the combination wireless internet and GPS. And it is also a location-based service system that can calculate the current position of the user by receiving a signal transmitted from a satellite, also includes positioning of each vehicle, and rapid mobilization in case of emergency. It also provides provision of the vehicle's operation history information, and the likes. Figure 5 shows the path of the patrol cars.

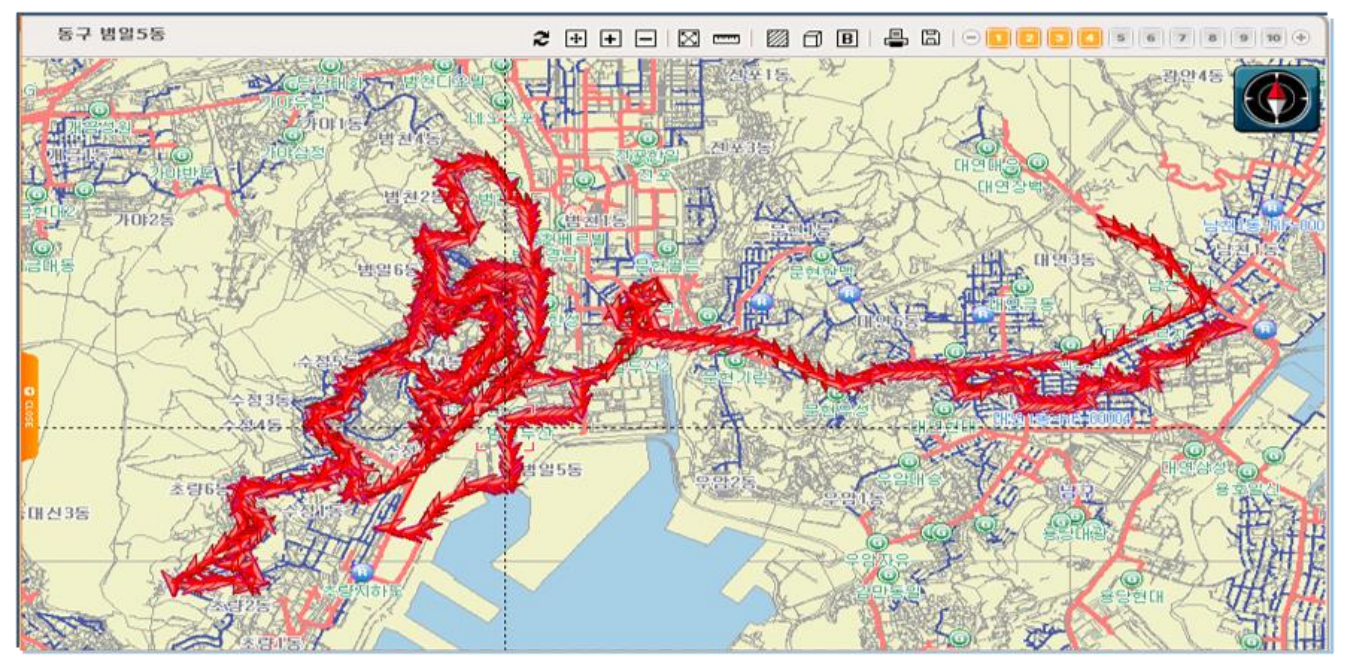

Figure 5. Path of the Patrol Cars

\subsection{3. e-GIS}

This e-GIS is a three-dimensional integrated safety management system to interconnect between enterprise resource planning (ERP) and facilities management information system based on GIS, and to dramatically improve business processes. For the city-gas process, the GIS-related supply process is based on a program that matches the user information, which forms the basis of the geographic information and the pipeline information, which is the major gas-supply facility. On this basis, this system implements a prototypical integration of data for the supply process. 


\section{Conclusions and Suggested Future Studies}

\subsection{Expected Effect of System Construction Results}

This paper suggests the efficient operation environment for the SDPS for minimizing accidents related to city-gas which are upward trends with the increase of gas consumption. As a results, this study will greatly contribute to the infrastructure construction for the scientific safety management, the advancement of the accident prevention system by construction of integrated GIS for underground facilities, the construction of the intelligent safety management system using IT technology and Big data, the disaster forecasting and prevention by fast and rapid decision-making and the operational Excellence in the city-gas industry.

\subsection{Conclusions and Suggested Future Studies}

This paper mentions how to effectively manage the buried pipelines and facilities of the city-gas for preventing the accidents and disasters. It also mentions how to detect gas leak and explosion status in real-time using the OS, AE and the ultrasonic technology, and to assess the influence range by the leak, explosion and fire of the city-gas. In addition, this paper suggests the system construction that can provide the quick response capability and needful information in real-time about any types of disasters and accidents, and the ways that could be linked to enable visual management by providing real-time information to the CEO, the manager and the operator $[2,6]$. Additionally, this paper does not, however, mention how to pinpoint the city-gas leak and explosion's initial point and develop the dedicated detection sensor for the Methane $\left(\mathrm{CH}_{4}\right)$ which is the main gas composition of the city-gas, along with the distance assessment from the city-gas leak and explosion point.

\section{References}

[1] K. J. Hyung, Y. B. Seok, K. J. Mo, K. S. Wook and K. J. Wook, "Consequence Analysis for Release Scenario of Buried High Pressure Natural Gas Pipeline", Journal of Korea Institute of Gas, vol. 18, no. 3, (2014), pp. 67-74.

[2] J. K. Lee and C. S. Kim, "An Implementation for Disaster Information Service and Search Function based on Smartphone Application”, Journal of Korea Multimedia Society, vol. 14, no. 5, (2011), pp. 703-709.

[3] K. J. Sun and K. Kyo, " Risk Ranking Analysis for the City-gas Pipeline in the Underground Laying Facilities”, Journal of Korean Institute of Fire Science \& Engineering, vol. 18, no. 1, (2004), pp. 54-66 1976-3751.

[4] Korea Gas Safety Corporation Editor, "Gas Accident Prevention Casebook", Korea Gas Safety Corporation Publishers, Chungbuk Korea, (2015).

[5] K. S. Park, "The Integrated Preventing System Construction Using Observation Explosion/Release for Urban Stability”, NEMA-06-MD-03, (2008), pp. 20-24.

[6] H. H. Lee, "Real-time Stochastic Optimum Control of Traffic Signals", Journal of Information and Communication Convergence Engineering, vol. 11, no. 1, (2013), pp. 30-44.

[7] National Institute of Chemical Safety Editor, "Technology Guidelines on Assessment of Accident Influence Range", National Institute of Chemical Safety Publishers, Daejeon Korea, (2015).

[8] Center for Chemical Process Safety Editor, "Guidelines for Process Safety Metrics “, Wiley Publishers, New York, (2009).

[9] K. Trevor, "Guideline for Technical Management for Chemical Process Safety", Journal of Loss Prevention in the Process Industries, vol. 4, no. 2, (1989), pp. 131-131.

[10] J. T. Gun, H. H. Suk and K. C. Soo, "A UIS-based System Development to Express the Damage History Information of Natural Disasters", Journal of Korea Multimedia Society, vol. 13, no. 12, (2010), pp. 1739-1747.

[11] Y. Y. Jae and Y. Y. Seop, "Emergency Monitoring System based on Newly-Developed Fall Detection Algorithm", Journal of Information and Communication Convergence Engineering, vol. 11, no. 3, (2013), pp. 199-206.

[12] J. G. Cheol, "SMART Factory", GS Intervision Publishers, Seoul Korea, (2011). 


\section{Authors}

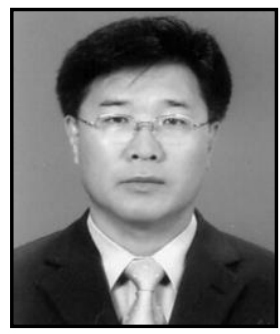

Park Jong Tak, Received B.S. and M.S. degrees in the Department of Mechanical Engineering from Yeung Nam University and Kumoh National Institute of Technology, Taegu and Kumi South Korea, in 1883 and 1997, respectively. At present he is taking a Ph.D. course at the Graduate School of MOT, Pukyong National University, Pusan South Korea. And he has been working at the Department of City-Gas Safety Management \& Engineering for 33 years since 1983. His major fields of study are Gas Safety Management, GIS Operation System, IT Convergence with gas safety, etc.

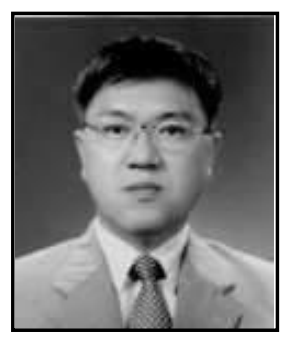

Kim Chang Soo, Received Ph. D. degree in the Department of Computer Engineering from Chung Ang University in 1991, Seoul Korea. He became a professor in the Department of IT Convergence and Application Engineering, Pukyong National University, Pusan South Korea, in 1992 and has continued until the present. He has been the Vice President of Korea Multimedia Society since 2011. His major fields of study are Disaster Prevention IT, UIS/GIS, Operation System, Semantic Web, Disaster Management, Space Search, Urban Disaster Prevention, etc.

i *Corresponding Author: Chang-Soo Kim( cskim@pknu.ac.kr) 